\title{
The Phytochemical and Antimicrobial Effect of Mango (Mangifera Indica L.) Peel Extracts on Some Animal Pathogens as Eco-Friendly
}

\section{Rehab Mohamed Atta El-Desoukey ${ }^{1 *}$, Norah Mohammed Aljor ${ }^{2}$ and Alanoud Daifallah Alaotibi ${ }^{2}$}

${ }^{1}$ Microbiology and Immunology Department, National Research Center, Giza, Egypt

${ }^{2}$ Biology Department, Faculty of Science and Humanities in Al Quwai'iyah, Shaqraa

University, KSA, Saudi Arabia

*Corresponding Author: Rehab Mohamed Atta El-Desoukey, Microbiology and Immunology Department, National Research Center, Giza, Egypt/ Shaqraa

University, KSA.
Received: February 17, 2020

Published: March 06, 2020

(C) All rights are reserved by Rehab Mohamed

Atta El-Desoukey., et al.

\section{Abstract}

A noticeable potency of many species of plants present against bacterial and fungal pathogens. Bacterial resistance against antibiotics is consider one among the common problems within the medical world, so one among the foremost important steps in microbiological researches is to seek out a replacement antimicrobial compound with minimal side effects. So the aim of this study is to research the antimicrobial activity of mango (Mangifera indica L.) peel aqueous and organic solvent extracts on some medically important animal pathogens and to work out some phytochemical compounds to be recycled to added in animals ration. Hot and cold aqueous additionally to ethanol extracts of mango (Mangifera indica L.) peel were evaluated for his or her antimicrobial activity against some medically important pathogens isolated from animals and poultry farms (Staphylococcus aureus, Escherichia coli, Pseudomonas aerogenes, Bacillus cereus and Candida albicans) by agar well diffusion method. Both hot, cold aqueous and ethanol peel extracts showed high antibacterial and antifungal effect against the all examined pathogenic samples. Also, phytochemical compound of aqueous and ethanol peel extracts were determined, results of the chemical tests explain the extracts of mango (Mangifera indica L.) peel contain alkaloids, flavnoids, tannins and saponin compounds. So it might be concluded that the mango (Mangifera indica L.) peel extracts possess remarkable antibacterial activity against gram positive and gram negative bacteria additionally to its antifungal activity against Candida albicans and to be introduced as an alternate to chemical antimicrobial drugs, is required wider investigation also ecologically as recycling of fruits peel are often used as artificial additive in animal ration.

Keywords: Mango; Antimicrobial; Extract; (Mangifera Indica L.); Fruits Peel; Eco-Friendly

\section{Introduction}

Microbes are the most common cause of infectious diseases which participate in about half of the deaths in human. As well as morbidity and mortality due to diarrhea in many developing countries which act as a major problem, The infections due to variety of bacterial etiologic agents such as pathogenic Escherichia coli (E. coli), Salmonella spp., and Staphylococcus aureus (S. aureus) are most common [1]. Also systemic fungal infec- tions due to Candida albicans (C. albicans) have emerged as important causes of morbidity and mortality [2].

The important food source for some crucial vitamins is fruits and veggies and also includes a sequence of bioactive additives, which would possibly have more than one effect in the fields of fitness $[3,4]$. Fresh, in juices, and cider fruits are one of kinds of fruit intake which includes mango. 
The introduction of antibiotic resistance of positive meals borne pathogens and the reluctance of customers toward consumption of chemically handled items have encouraged the improvement of secure and herbal antimicrobials for meals merchandise and remedy of various illnesses [5]. Fruit peels are considered to be novel, effortlessly to be had, green, lowcost, eco-friendly, natural and financial source for antioxidants and antimicrobial marketers and mango peel is one in all them. Mango (Mangifera indica L.), which belongs to the circle of relatives Anacardiaceae, is one of the most cultivated fruit in the international. Several million tons of mango wastes are produced yearly from factories. Peel which might be considered to be by means of-merchandise from industrial processing or consumption of the fruit contributes about $15-20 \%$ of the fruit that's generally discarded as waste $[6,7]$.

Recently, mango peels have attracted full-size attention in the medical community because of their high content of precious compounds, such as phytochemicals, polyphenols, carotenoids, enzymes, diet $\mathrm{E}$ and diet $\mathrm{C}$ that have principal useful and antioxidant homes $[8,9]$.

Efforts are constantly taken to improve approaches for correct usage of end result and greens wastes which is causing a severe disposal problem. The reutilization of biological wastes is of outstanding hobby considering the fact that, due to legislation and environmental reasons, the industry is progressively subjected to find an opportunity use for its residual rely i.E. Seed and peels.

More over traditional natural therapy can be a satisfying alternative in which some of the pathological situation where the scientific capsules become crippled but demands an sufficient amount of studies [10].

So the goal of this study is to research the antimicrobial hobby of mango (Mangifera indica L.) peel aqueous and organic solvant extracts on a few medically vital animal pathogens and to determine some phytochemical compounds to be recycled to introduced in animals ration.

\section{Materials and Methods}

1. Collection of plant substances: Mango (Mangifera indica $\mathrm{L}$.) used on this examine had been acquired from nearby marketplace in Alquieiya, KSA 2017.
2. Aqueous extraction: Distilled water changed into boiled (10 $\mathrm{ml}$ ), (about $5 \mathrm{gm}$ of) dried plant peel have been introduced to the water and left to cool. Then were combined by way of the blender and filtered to get clear aqueous extracts (concentration about $50 \%$ ). The extracts were saved at $4{ }^{\circ} \mathrm{C}$ until to be use. But the recent aqueous extract has been organized immediately after boiling and filtration in line with [11].

3. Solvent extract: Five g of dried plant peel changed into extracted with $10 \mathrm{ml}$ of each solvent (Ethanol) saved for $24 \mathrm{~h}$. Then, it changed into filtered the usage of Watman No.1 filter out paper. The solvent become evaporated to make the final quantity as half of of the authentic (concentration about 50\%) according to [12].

4. Preparation of inoculums: The inoculums (bacterial traces and fungi) had been isolated from large animals and chicken farms on the outskirts of Cairo. The traces of micro organism (Staphylococcus aureus, Escherichia coli, Pseudomonas aerogenes, Bacillus cereus) and fungi (C. Albicans) had been inoculated Sabaroud dextrose agar (SAB) (Purchased from Witan - Biolife Company produced with the aid of Jalil Medicals Company) and nutrient broth (Purchased from Witan - Biolife Company produced via Jalil Medicals Company).For overnight at $37^{\circ} \mathrm{C}$ for micro organism and $25^{\circ} \mathrm{C}$ for fungi in keeping with [11].

5. Antimicrobial screening: The agar well diffusion approach changed into used for the willpower of antibacterial interest of mango (Mangifera indica L.) peel aqueous extracts further to ethanol extract with the aid of using bacterial isolates taken from animals and hen (Staphylococcus aureus, Escherichia coli, Pseudomonas aerogenes, Bacillus cereus) and fungi (C. Albicans) to evaluate its effects on the isolated bacteria.

Loopfull boom from bacterial isolate became inoculated into nutrient broth incubated at $37^{\circ} \mathrm{C}$ for 18 hours. The dilution of bacterial suspensions with everyday saline. Adjust the turbidity and compare with popular tube (McFarland quantity 0.5) to get a uniform suspension containing $1.5 \times 108 \mathrm{CFU} / \mathrm{ml}$. Muller- Hinton agar was inoculated with zero. $1 \mathrm{ml}$ of bacterial inoculum. Using cork borer, wells were made on the classy media. The aqueous and solvent extracts had been considered as the $50 \%$ awareness. Then, $0.1 \mathrm{ml}$ of extracts have been delivered to wells, then the plates left for $30 \mathrm{~min}$ in fridge at four ${ }^{\circ} \mathrm{C}$, thereafter, they have been incubated at $37^{\circ} \mathrm{C}$ for twenty-four hrs. The pastime of extracts changed into determined 
by measuring the diameter of inhibition quarter in millimeter. All experiments were duplicated. Ciprofloxacin (10 $\mu \mathrm{g})$ and penicillin $(10 \mu \mathrm{g})$ used as positive manage even as distilled water $(100$ $\mu \mathrm{g}$ ) used as terrible manipulate for antibacterial screening aqueous extract. Nystatin $(10 \mu \mathrm{g})$ changed into used as high quality manipulate at the same time as distilled water (a hundred $\mu \mathrm{g}$ ) used as negative manage for antifungal screening. All chemicals used (Purchased from Witan - Biolife Company produced with the aid of Jalil Medicals Company) [11,13].

\section{Phytochemical tests}

1. Tannins test: Amodified strategies stated in $[11,13]$ changed into used to bepresented of tannins at the extracts, A few drops of Ferric chloride reagentwere brought for three ml of extract. A blueblack color refereed to the gift of tannins.

2. Alkaloids test: A few drops of Marqus reagent (organized from blending 0.Five $\mathrm{ml}$ of Formaldehyde with $5 \mathrm{ml}$ of attention H2SO4), delivered to the $5 \mathrm{ml}$ of extract. Turbidity refereed to the present of alkaloids $[11,14]$.

3. Saponins test: $3 \mathrm{ml}$ of extract became added to the $2 \mathrm{ml}$ of Ferric chloride, a white residue to be fashioned as evidence to the existing of Saponins $[11,14]$.

4. Flavonoids test: Flavonoids check have been enforce in conformity with $[11,15]$. $2 \mathrm{ml}$ of extract blend with Alcoholic $\mathrm{KOH}$ (zero. Five mol.), a yellow color as proofed to the existing of Flavonoids.
5. Glygosides test: $0.5 \mathrm{~g}$ of grinded mango (Mangifera indica L.) dried peel changed into dissolved in $2 \mathrm{ml}$ of glacial acetic acid containing one drop of Ferric chloride answer, andthen underlaidwith $1 \mathrm{ml}$ of attention H2SO4A brown ring indicated the existing of Glycosides $[11,16]$. All chemical compounds used (Purchased from Witan - Biolife Company produced by Jalil Medicals Company).

\section{Results}

The effects given in (Table 1) imply that the new and cold aqueous similarly to ethanol extracts of mango (Mangifera indica L.) dried peel had been evaluated for its antimicrobial activity in opposition to some medically important pathogens remoted from animals and chicken farms micro organism (Staphylococcus aureus, Escherichia coli, Pseudomonas aerogenes, Bacillus cereus) and fungi (C. Albicans) by means of agar properly diffusion technique. The ethanol peel extracts showed high antibacterial and antifungal effect against the all tested pathogenic samples whoever warm aqueous extract confirmed excessive antibacterial and antifungal impact besides on E. Coli, also cold aqueous extract showed impact only on Bacillus, E.Coli and C. Albicans. Also, phytochemical compoud of aqueous and ethanol peel extracts had been decided, consequences of the chemical exams give an explanation for the extracts of mango (Mangifera indica L.) peel comprise alkaloids, flavnoids, tannins and saponin compounds as proven in (Table 2).

\begin{tabular}{|l|c|c|c|c|c|c|}
\hline \multirow{2}{*}{$\begin{array}{l}\text { Examined Fruits and Vegetables } \\
\text { Peels Powder }\end{array}$} & \multirow{2}{*}{ Types of Extracts } & \multicolumn{5}{|c|}{ Types of Examined Microbes } \\
\cline { 3 - 7 } & & S aures & Bacillus & E coli & Ps. eurogenes & C albicans \\
\hline \multirow{3}{*}{ mango (Mangifera indica L.) } & Hot aqueous extract & 17 & 16 & 0 & 15 & 15 \\
\cline { 2 - 7 } & Cold aqueous extract & 0 & 21 & 16 & 0 & 12 \\
\cline { 2 - 7 } & ethanol & 22 & 18 & 18 & 16 & 30 \\
\hline Control +ve & Ciprofluxacin & 25 & 34 & 20 & 22 & 0 \\
\hline Control +ve & Bacitracin & 33 & 36 & 17 & 0 & 16 \\
\hline Control +ve & Nystatin & 0 & 0 & 0 & 0 & 0 \\
\hline Control -ve & Distelled water & 0 & 0 & 0 & 0 & 0 \\
\hline
\end{tabular}

Table 1: Antimicrobial activity of mango (Mangifera indica L.) peel aqueous and ethanol extracts against some animal pathogen in ( $\mathrm{mm})$. 


\begin{tabular}{|l|c|}
\hline $\begin{array}{l}\text { Plant Extracts } \\
\text { Phytochemical Tests }\end{array}$ & Mango (Mangifera indica $L$.) \\
\hline Flavonoids Test & + \\
\hline Alkaloids Test & + \\
\hline Glygosides Test & + \\
\hline Saponins Test & + \\
\hline Tannins Test & + \\
\hline
\end{tabular}

Table 2: The phytochemical compounds in mango (Mangifera indica L.) peel aqueous extracts

+ (contain this phytochemical compound).

\section{Discussion}

From the historic time exceptional cultures around the world have used herbs and plants as a treatment in distinctive diseased circumstance and hold health. Many capsules prescribed today in contemporary medicinal device are derived from plants. Synthetic drug is known for its toxicity which now and again needs extreme clinical interest. So within the current beyond the practice of herbalism has got popularity around the world such as the advanced international locations due to its potency and apparent protection profile. Medicinal flora play a key function in human fitness care. About $80 \%$ of the world population is based on using conventional remedy, that's predominantly based totally on plant fabric. Scientific studies to be had on medicinal plant life suggest that promising phytochemicals may be evolved for many fitness issues $[17,18]$. More over some of the pathological circumstance where the scientific pills turn out to be crippled but traditional natural therapy can be a fulfilling alternative which needs an ample quantity of research [15]. The use of and look for drugs and nutritional dietary supplements derived from vegetation have improved in latest years. Ethnopharmacologists, botanists, microbiologists, and herbal-merchandise chemists are combing the Earth for phytochemicals and "leads" which can be evolved for remedy of diseases [19].

Peels of various fruits and greens are commonly taken into consideration as waste product and are generally thrown away through us. But distinct studies carried out on peels revealed the presence of vital ingredients, which can be used for pharmaceutical purpose. Number of components having activities like antioxidant, antimicrobial, antiinflammatory, antiproliferative and so forth. Were isolated from extraordinary peels [20]. The gift study aimed to analyze the antimicrobial activity of mango (Mangifera indica $L$.) peel aqueous and natural solvant extracts on some medically essential animal pathogens and to decide some phytochemical compounds to be recycled to delivered in animals ration.

Mango is local to tropical areas of worldwide and India ranks first in its production. Mango, being a seasonal fruit, is processed for diverse merchandise which include puree, leather-based, nectar, pickles, canned slices and pickles which have global reputation [8]. Antioxidant activity of peels of ripe and uncooked mango in acetone extract turned into decided the usage of unique antioxidant models consisting of lowering electricity hobby, DPPH loose radical scavenging interest, soybean lipoxygenaseinhibition, iron triggered lipid peroxidation of liver microsomes. Results confirmed that the IC50 values were in the range of one.39-5.24 lg of gallic acid equivalents. On phytochemical evaluation acetone extract of mango peel became located to include polyphenols, anthocyanins and carotenoids [6]. In any other look at, the loose radical scavenging sports of mango flesh and peel extracts had been evaluated by using electron spin resonance and it became determined that mango peel extract exhibited more potent loose radical scavenging ability on 1, 1-diphenyl-2-picrylhydrazyl and alkyl radicals than mango flesh extract without any relation to its ripeness [9].

Mango peel is a rich supply of phenolic compounds, which show off antioxidant hobby [21]. The most important phenolic compounds found in mango peel extract are said to be syringic acid, quercetin, mangiferin pentoside and ellagic acid [8]. Phenolic compounds are located to have antiviral, antibacterial and anti inflammatory pastime [22].

Ethyl acetate fraction and ethanol crude extracts of mango peel are reported to showcase strong antifungal activity towards pathogenic fungus inclusive of Rhizoctonia solani [23]. In case of unripe mango peel, superior fungal inhibition become observed with $95 \%$ methanol extract than ninety five\% ethanol extract and the inhibition of methylene chloride extract become more than ethyl acetate [24]. The $\sim 159 \sim$ principal aspect for antifungal pastime was discovered to be five- (12-heptadeconyl)-resorcinol [25].

In agreement with the previous results as shown in (Table 1) imply that the hot and cold aqueous similarly to ethanol extracts of mango (Mangifera indica L.) dried peel were evaluated for its antimicrobial effect against a few medically crucial pathogens remoted 
from animals and chicken farms bacteria (Staphylococcus aureus, Escherichia coli, Pseudomonas aerogenes, Bacillus cereus) and fungi (C. Albicans) by agar well diffusion approach. The ethanol peel extracts showed high antibacterial and antifungal impact towards the all examined pathogenic samples whoever hot aqueous extract confirmed excessive antibacterial and antifungal effect besides on E. Coli, additionally cold aqueous extract showed effect most effective on Bacillus, E. Coli and C. Albicans In widespread, the Gramwonderful lines of micro organism tested regarded to be more sensitive to the extracts. However, this take a look at additionally facts a full-size susceptibility of some of the tested Gram-poor bacteria. According to literature, the antimicrobial interest may be inspired through the phenolic compounds [3,17-19]. Culmination, as wealthy assets of phenolic compounds have been paid a unique interest [3,26-28].

Kim., et al. [29] and Kim. et al. [30] who tested the antioxidant ability of ripened and unripened peels of various mango cultivars via overall phenolic estimation. They found better general phenolic content material ninety - one hundred ten $\mathrm{mg} / \mathrm{g}$ in ripened peels compared to uncooked 55 - $85 \mathrm{mg} / \mathrm{g}$ on dry foundation. They concluded that the entire phenolic contents had been laid low with adulthood degree, cultivar type and agronomic practices. The high bioactive and phytochemical content of mango peels may additionally sell their use as antioxidant, antiproliferative, antimutagenic and different health promoting houses [8, 31].

In regard to the previous outcomes. Phytochemical compoud of aqueous and ethanol peel extracts were determined, results of the chemical tests give an explanation for the extracts of mango (Mangifera indica L.) include alkaloids, flavnoids, tannins and saponin compounds as shown in (Table 2).These findings are in agreement with measured total phenolic contents of the samples [3,29-31].

\section{Conclusion}

The unsafe effects of synthetic antioxidants and the emergence of antibiotic resistant traces have revived the search for antioxidant and antimicrobial marketers from natural sources. From exclusive research performed on peels, it's been located that peels of culmination and veggies maintain a splendid capability to function a supply of newer, effective, more secure and higher antioxidant and antimicrobial sellers. The gift look at virtually highlights that mango peel powder possess brilliant nutraceutical potential which become exhibited through its effective antimicrobial pastime in opposition to various food borne pathogens thereby indicating its use as a nutritional and healing agent in meals industry. The have a look at additionally recommends the use of mango peel powder in daily existence recipes as it enriched the recipes nutritionally and additionally gave an precise flavor and flavour to the dishes and in ration for animals. Additionally, utilization of mango peels no longer only promotes fee addition but also allows to lessen waste generation, environmental pollution and reduced value in waste disposal.

\section{Bibliography}

1. Parastoo Karimi Alavijeh., et al. "A study of antimicrobial activity of few medicinal herbs". Asian Journal of Plant Science and Research 2 (2012): 496-502.

2. Piddock KJV and R Wise. "Mechanism of resistance of quinolones and clinical perspective". Journal of Antimicrobial chemotherapy 23 (1989): 475-483.

3. Sara Jelodarian., et al. "Evaluation of antimicrobial activity of Malus domestica fruit extract from Kashan area Avicenna". International Journal of Phytomedicine 3.1 (2013): 1-6.

4. Yigit D., et al. "Antioxidant and antimicrobial activities of bitter and sweet apricot (Prunus armeniaca L.) kernels". Brazilian Journal of Medical and Biological Research 42 (2009): 346-352.

5. Jadhav S., et al. "Inhibitory activity of yarrow essential oil on Listeria planktonic cells and biofilms". Food Control 29 (2013): 125-130.

6. Beerh OP., et al. "Utilization of mango waste: recovery of juice from waste pulp and peel". Journal of Food Science and Technology 13 (1976): 138-141.

7. Priyanka Asai Thambi., et al. "Antimicrobial efficacy of mango peel powder and formulation of recipes using mango peel powder (Mangifera indica L.)". International Journal of Home Science 2.2 (2016): 155-161.

8. Ajila CM., et al. "Mango peel powder: A potential source of antioxidant and dietary fiber in macaroni preparations". Innovative Food Science and Emerging Technologies 11 (2010): 219-224.

9. Kim HJYH., et al. "Antioxidant and antiproliferative activities of mango (Mangifer aindica L.) flesh and peel". Food Chemistry 121 (2010): 429-436. 
10. Gupta M., et al. "Therapeutic utilization of secretory products of some Indian medicinal plants: A review". Indian Journal of Traditional Knowledge 5.4 (2006): 569-575.

11. Rehab Mohamed Atta El-Desoukey. "phytochemical and antimicrobial activity of panicum turgidum (thummam) as a grazing herb against some animal pathogens)". EC Microbiology 5.1 (2017): 22-29.

12. Rehab Mohammed Atta El Desoukey. "Phytochemical and Antimicrobial Activity of Medicago sativa (Alfalfa) as Source of Animal Food Against Some Animal Pathogens". Global Veterinaria 14.1 (2015): 136-141.

13. Kanife UC. "Potentials of alkaloids from Panicum maximum florets infected with the fungus Tilletia ayresii in controlling uterine contraction in Sprague- dawley rats". Ph.D Thesis University of Lagos (2011).

14. Ajoku GA., et al. "Foliar Ultra-Structure and Antimicrobial screening of the Leaf Extracts of Panicum maximum Jacq. (Family: Poaceae/Graminae)". Scholarly Journal of Biological Science 4.3 (2015): 19-22.

15. Doss A., et al. "Antibacterial evaluation and phytochemical analysis of certain medicinal plants". Journal of Biological Research 1 (2011): 24-29.

16. Antia BS., et al. "Antidiabetic activity of Panicum maximum". International Journal of Drug Development and Research 2.3 (2010): 488- 492.

17. Vaibhav Patel., et al. "Phytochemical and Pharmacological Profile of Malus Domestica: An Overview". International Journal of Current Pharmaceutical Research 2.2 (2012): 334-338.

18. Adewusi EA and Afolayan AJ. "A review of natural products with hepato protective activity". Joint Meeting on Pesticide Residues 4.13 (2010): 1318-1334.

19. Gupta M., et al. "Therapeutic utilization of secretory products of some Indian medicinal plants: A review". Indian Journal of Traditional Knowledge 5.4 (2006): 569-575.

20. Sonia Parashar., et al. "Antimicrobial and Antioxidant activities of fruits and vegetable peels: A review". Journal of Pharmacognosy and Phytochemistry 3.1 (2014): 160-164.

21. Palmeira SMV., et al. "Extraction of phenolic compounds from mango peels". Latin American Applied Research 42 (2012): 7781.

22. Zgórka G and Kawka S. "Application of conventional UV, photodiode array (PDA) and fluorescence (FL) detection to analysis of phenolic acids in plant material and pharmaceutical preparation". Journal of Pharmaceutical and Biomedical Analysis 24 (2001): 1065-1072.
23. Qin LJ., et al. "Stability of antimicrobial activities of mango (Mangifera indica L.) peel extracts". Guangxi Agricultural Sciences 4 (2007a): 423-426.

24. Qin LJ., et al. "Preliminary study on antifungal activities of different extracts of the peel of mango (Mangifera indica L.)". Chinese Journal of Tropical Agriculture 2 (2007b): 21-25.

25. Cojocaru M., et al. "5- (12-heptadeconyl)-resorcinol, the major component of the antifungal activity in the peel of mango fruit". Phytochemistry 25 (1986): 1093-1095.

26. Robards K., et al. "Phenolic compounds and their role in oxidative processes in fruits”. Food Chemistry 66 (1999): 401-436.

27. Kalt W., et al. "Antioxidant capacity, vitamin C, phenolics,and anthocyanins after fresh storage of small fruit". Journal of Agricultural and Food Chemistry 47.11 (1999): 4638-4644.

28. Wang SY and Lin HS. "Antioxidant activity in fruits and leaves of blackberry, rasberry, and strawberry varies with cultivar and developmental stage". Journal of Agricultural and Food Chemistry 48 (2000): 140-146.

29. Kim Y., et al. "Antioxidant phytochemical and fruit quality changes in mangoes (Mangifera indica L.) following hot water immersion and controlled atmosphere storage". Food Chemistry 105 (2007): 1327-1334.

30. Kim Y., et al. "Antioxidant phytochemical and quality changes associated with hot water immersion treatment of mangoes (Mangifera indica L.)". Food Chemistry 115 (2009): 989-993.

31. Ajila CM., et al. "Valuable components of raw and ripe peels from two Indian mango varieties". Food Chemistry 102 (2007): S1006-1011.

\section{Assets from publication with us}

- Prompt Acknowledgement after receiving the article

- Thorough Double blinded peer review

- Rapid Publication

- Issue of Publication Certificate

- High visibility of your Published work

Website: https://www.actascientific.com/

Submit Article: https://www.actascientific.com/submission.php Email us: editor@actascientific.com

Contact us: +919182824667 